\section{Revista Brasileira de Administração Científica}

Brazilian Journal of Scientific Administration

Mai a Ago 2018 - v.9 - n.2
ISSN: 2179-684X

\title{
Influência da interatividade nas mídias sociais no consumo de viagens
}

O setor de serviços recebe cada vez mais destaque na economia global, com participação nos produtos internos brutos acima da produção de bens em grandes países industrializados, como EUA e Reino Unido. Os serviços relacionados à manutenção das instalações, em especial, representam sempre um grande dispêndio de recursos para as organizações, já que são atividades de natureza indispensáveis para o desenvolvimento de qualquer organização. Nesse segmento, enquadrase a MGS, empresa pública do Estado de Minas Gerais, a qual a medição da qualidade dos serviços prestados aos clientes através do instrumento SERVPERF é o objetivo desse artigo. Aferir a qualidade de serviços é um grande desafio para as empresas, certamente mais difícil do que realizar a mesma aferição na produção de bens. Diante dos resultados, foi possível verificar que os serviços da MGS apresentam um nível de qualidade aceitável sendo possível inferir que, se não há satisfação plena, os clientes também não estão insatisfeitos com a qualidade dos serviços. Além disso, destaca-se que a confiabilidade do questionário aplicado foi atestada, considerando os resultados alcançados pelo alfa de Cronbach. A medição e acompanhamento da qualidade são passos fundamentais para a busca de melhoria contínua, e consequentemente o alcance da satisfação por parte dos clientes e devem ser tomados como desafios por qualquer organização que busque o sucesso.

Palavras-chave: Interatividade; Mídias sociais; Consumo; Viagens.

\section{Influence of interactivity on social media in travel consumption}

This article seeks to understand how interactivity between social media users influences travel consumption habits. To this end, aspects of influence on trave consumption were identified and classified using online media Instagram. From the perspective of methodological procedures, nine interviews were conducted with Instagram users. The first individuals interviewed were chosen because the researchers had prior knowledge that they were Instagram users and follow other users who post content from travel images they carry out. From then on, the snowball technique was used to identify other subjects for the investigation. The methodology adopted includes qualitative procedures using the content analysis proposed by Bardin (2011), including the analysis and categorization procedures. The results identified that the habit of interacting in social networks makes the users of Instagram, while sharing images of their trips, become active promoters of tourism. The intangibility of the tourist destination benefits from this visual exposure via social networks, making it a tangible image and allowing a virtual experience through Instagram. The formation and perception of the image of a tourist destination through this social network bring the individuals close to their peers, exhibiting trips and experiences of friends and the like.

Keywords: Interactivity; Social media; Consumption; Travels.

Topic: Marketing e Estratégias Mercadológicas

Reviewed anonymously in the process of blind peer.
Received: 07/05/2018

Approved: $15 / 07 / 2018$
Natália Lopes Mesquita Assunção

Universidade Estadual do Ceará, Brasil

http://lattes.cnpq.br/3582148890505936

nahtinhamesquita@hotmail.com

Joanice Maria Araújo Diniz

Universidade de Fortaleza, Brasil

http://lattes.cnpq.br/7335548485853992

joanicediniz@gmail.com

Danielle Miranda de Oliveira Arruda

Universidade Estadual do Ceará, Brasil

http://lattes.cnpq.br/73355548485853992

danielle.gomes@uece.br

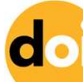

DOI: 10.6008/CBPC2179-684X.2018.002.0003
Haroldo de Sá Medeiros

Universidade Federal de Rondônia, Brasil

http://lattes.cnpq.br/2039274371515784

haroldo_sm@hotmail.com

\section{Referencing this:}

ASSUNÇÃO, N. L. M.; DINIZ, J. M. A.; ARRUDA, D. M. O.; MEDEIROS, H. S.. Influência da interatividade nas mídias sociais no consumo de viagens. Revista Brasileira de Administração Científica, v.9, n.2, p.2635, 2018. DOI: http://doi.org/10.6008/CBPC2179-684X.2018.002.0003 


\section{INTRODUÇÃO}

A interatividade nas mídias sociais influencia os consumidores. Essa influência parte dos grupos de referência, composto por usuários influentes ou amigos usuários, que são pontos de comparação para a formação de valores e atitudes gerais, servindo como guias específicos de comportamento no consumo (SCHIFFMAN et al., 2009).

Por meio de poucos cliques, pode-se acompanhar de maneira quase gratuita o comportamento de amigos, familiares e formadores de opinião. Demonstram-se sentimentos por manter relações e conexões com seus semelhantes, de modo que as opiniões desses grupos de referência têm um peso importante e podem ajudar no processo de decisão de compra ou contratação de um serviço. No âmbito específico da relação entre a atividade turística e a interatividade nas mídias sociais, entende-se que sua conexão reside na busca dos usuários por informações que influenciam a o processo decisório de consumo e na escolha de práticas mercadológicas por parte das empresas para influenciar os consumidores (SANTOS et al., 2017).

Por outro lado, além da influência das buscas e das práticas mercadológicas das empresas, a atividade turística também é influenciada pelo alto nível de interatividade entre os próprios usuários de mídias sociais (MKONO et al., 2016), havendo semelhança ao panorama geral descrito por Schiffman et al. (2009). Para Mkono et al. (2016), além dos familiares, amigos e formadores de opinião, esses grupos de influência se tornaram mais amplos, sendo formados por outros usuários que compartilham as suas experiências turísticas anteriores, residindo na necessidade de entendimento sobre esta forma interação o foco deste artigo.

Ao questionar 'como a interatividade nas mídias sociais virtuais influencia o consumo de viagens?', pretende-se compreender as formas nas quais a interação entre os usuários de mídias sociais pode influenciar o consumo de produtos e serviços turísticos. Assim, para auxiliar na consecução do atendimento ao objetivo geral, foram identificados e classificados os aspectos de influência no consumo de viagens utilizando a mídia online Instagram.

Justifica-se esta problemática na tentativa de preencher parte da lacuna no conhecimento existente sobre a dinâmica das mídias sociais como um ambiente colaborativo, no qual há uma expansão dos atores e das formas interativas que influenciam o consumo. Este fenômeno pode isto ser visto em mídias distintas e com análises diversas nos trabalhos de Daries-Ramon et al. (2017) e Mkono et al. (2017).

A escolha do Instagram como rede social para análise se dá devido ao espaço que este aplicativo oferece para elementos visuais e projeção de imagens como fotografias, ilustrações e vídeos. Os usuários, amigos ou seguidores, desenvolvem um tipo de interação que vai além de postagem de conteúdo e visualização, com curtidas, comentários, marcação de pessoas, legendas, adição de mapa, interatividade com outras redes sociais e uso de hashtags. Desta forma, compreende-se que é uma unidade de análise adequada.

\section{REVISÃO TEÓRICA}

A influência da Internet modifica o modo de comunicação praticada no século XX pelos tradicionais meios de comunicação de massa mediadores de informação, como televisão e jornal impresso, os quais 
geravam informações e tinham como público alvo um leitor, espectador passivo. Esta transformação envolve uma transição de produção, armazenagem e distribuição de informação e entretenimento digitais (WOLTON, 2003). Se antes não havia contribuição, hoje o internauta consome, gera informação e interage, sendo a interação a principal característica da internet.

Os meios de comunicação de massa, que praticavam o controle da transmissão de informações, agora concorrem com a Internet no acesso e fornecimento qualificado de informações ao cidadão, que está mais ativo, colaborativo e, exigente (DUARTE, 2012). Diante o exposto, a sociedade consome informação tanto analógica quanto digital e o modelo de comunicação que garante maior sucesso de interação é alcançado, particularmente, via redes sociais.

Como resultado do surgimento desta nova fase da Internet, encontra-se a ampliação das possibilidades de produção noticiosa, com novas e notáveis ferramentas capazes tanto de ampliar o trabalho de geração e distribuição de conteúdo, como de permitir a qualquer pessoa também assumir este papel. 0 ambiente online possui enorme capacidade de garantir o compartilhamento de informações e a interlocução entre os envolvidos. O conteúdo disponibilizado é passível de críticas, sugestões e o feedback pode ser dado em tempo real.

As novas mídias sociais, entendendo-as como meios de comunicação que permitem a emergência das redes sociais, precisam subverter a lógica da mídia de massa (um para todos) para a lógica da participação (todos para todos) (RECUERO, 2009). Deste modo, as redes sociais, possibilitaram espaço para que os usuários compartilhassem cada vez mais conteúdo individual, subjetivo, a respeito de si mesmos, seus atos, e escolhas, o que inclui seus objetos de consumo. Os usuários não se contentam apenas em serem consumidores e espectadores da publicidade. Querem publicitar a si mesmos, engajar-se junto às marcas favoritas, tornarem-se mercadorias vendáveis, atrair seguidor-consumidores daquilo que produzem, angariar aprovações (likes) para si mesmos e, como consequência, potencialmente aumentam a presença digital dessas marcas (SALAZAR,2014). As ações nas mídias sociais visam promover experiências e interações diretas entre a marca e o usuário, fortalecendo na mente do consumidor, conceitos ou reforços intangíveis que venham à tona do momento de decisão (MOURA, 2009).

As novas tecnologias relacionadas ao processo de comunicação digital se sucedem e torna-se difícil acompanhar a evolução e o surgimento de produtos de comunicação relacionados aos computadores, telefonia, tablets, TVs, smartphones, ao ponto de, em alguns momentos, um executar a tarefa original do outro. Desta forma o resultado desta integração digital é uma sociedade permanentemente interligada, que se acostumou e exige acesso fácil, atendimento, acessibilidade e presteza que gera a necessidade de investindo não apenas em tecnologia, mas na filosofia de transparência (DUARTE, 2012).

Com a troca de informações sendo um dos principais valores da sociedade contemporânea, a tecnologia digital surge suprindo esta demanda, assim internet é espaço de lazer e socialização. A capacidade de armazenamento é mais uma vantagem das mídias sociais, ao contrário de relacionamentos offline, as conversas e conexões ficam registradas e não desaparecem. Estas conversas armazenadas podem ser acessadas em outros momentos, por diferentes grupos e pessoas, e acabam transcendendo o grupo de 
origem, navegando pelas conexões das redes sociais e ampliando a audiência e a participação dos demais, que caracteriza as conversações em rede (RECUERO, 2013).

Se antes a sociedade tinha a conversação como a principal fonte de interação, com a internet, "a conversação é um fenômeno emergente nos sites de rede social na atualidade, que enfoca as apropriações dessas redes para a interação" (RECUERO, 2013). A interação, então, passou a superar a conversação no sentido de oralidade. A comunicação verbal via texto, agora se realiza através de qualquer ação que simbolize participação, tomada de turno, como curtidas, compartilhamentos, marcação de pessoas e comentários.

A transmissão de imagens, especialmente fotografias, nas mídias sociais, também possibilita a interação entre seus usuários (FONTCUBERTA, 2012). O compartilhamento de fotografias funciona então como novo sistema de comunicação social, de etiqueta e cortesia. As plataformas de sites de redes sociais permitem aos internautas construir interações, negociar com os pares de forma criativa ao estabelecer diálogo sobre o conteúdo de uma imagem publicada por um ator, opiniões e valores são emitidos, diversos usuários podem se envolver, construindo uma interação mútua, dialógica (FREITAS et al., 2012).

\section{METODOLOGIA}

A partir de uma perspectiva ontológica múltipla, em que a subjetividade individual se configura em um dos aspectos que dificulta a determinação de uma realidade objetiva (COLLIS et al., 2005), esta pesquisa busca, por meio de uma abordagem qualitativa, compreender como a interatividade de pessoas em ambiência online influencia hábitos de consumo de viagem. Esta abordagem apresenta-se adequada ao objetivo de estudo por proporcionar uma maior aproximação entre objeto e sujeito investigador (DENZIN et al., 2006), possibilitar a compreensão de aspectos subjetivos intrínsecos à própria realidade subjetiva que escapam das análises quantificadoras (MESQUITA et al., 2014), além de fazer uso de arsenal de técnicas de coleta de dados que podem incluir entrevistas, observações e análise documental (PATTON, 2002).

O corpus da pesquisa é estruturado com base nas etapas e procedimentos propostos por Bauer et al. (2012), quais sejam: a seleção preliminar dos sujeitos a serem pesquisados; a análise da variedade destes sujeitos; e a ampliação deste corpus de dados até um ponto de saturação teórica, onde não há mais variedade ou elas são mínimas.

Os sujeitos foram escolhidos por critérios de acessibilidade e disponibilidade para participar do estudo. As primeiras pessoas que participaram desta pesquisa como sujeitos foram aquelas que os pesquisadores têm conhecimento que fazem uso do Instagram e, nesta rede social virtual, seguem outros usuários que publicam conteúdo de imagens de viagens que realizam. A partir de então foi utilizada a técnica de bola de neve (snowball) para identificar outros sujeitos para a investigação. Esta técnica possibilita que os indivíduos pesquisados indiquem outros que se encaixem no mesmo perfil procurado e que estes indiquem mais outros, aproveitando-se da rede social dos entrevistados (ATKINSON et al., 2001).

A coleta de dados aconteceu utilizando-se técnicas de entrevistas durante a abordagem do sujeito. Foram realizadas nove entrevistas em contato direto e gravadas em aparelho de captura de áudio. A média de tempo das entrevistas foi de 28 minutos. Para esta forma de coleta de dados foi utilizado o tópico guia 
que direciona a conversa, 'fornecendo uma progressão lógica e plausível através dos temas em foco' além de funcionar como "um esquema preliminar para a análise das transcrições" (GASKELL, 2012). Os sujeitos foram questionados sobre o seu 'uso' do Instagram. O material coletado foi transcrito, analisado e categorizado a partir das temáticas empíricas emergentes nos discursos com o uso da técnica exploratória de análise de conteúdo (BARDIN, 2011).

\section{RESULTADOS E DISCUSSÃO}

A análise do material coletado possibilitou a divisão em algumas categorias empíricas que são expostas nesta seção. Para fins de identificação, os respondentes serão indicados pela letra 'E' seguida de número correspondente à ordem alfabética. Os recortes apresentados a seguir indicam alguns dos hábitos identificados. A primeira categoria da pesquisa corresponde em identificar entre os entrevistados se o Instagram influenciava na decisão/intenção de viagem.

Tenho (vontade de viajar ao ver viagens no Instagram) com certeza. Quando eu vejo algumas imagens eu fico com vontade imediata (E1).

[...] eu acho que há vontade de conhecer... Você vê as pessoas num passeio, ou em um restaurante, ou numa festa... Aí eu acho que dá vontade, né? E você também quer compartilhar (E2).

Tem gente que mora fora que eu sigo que eu acho muito legal e tenho vontade de visitar o local (E5).

Estes primeiros trechos referem-se aos sentimentos gerados nos entrevistados a partir da visualização de postagens no Instagram. O que descrevem traz relatos de vontades, desejos, sincronia e proximidade percebida que demonstra a influência das imagens publicadas na rede social como uma força geradora destes sentimentos. Para seleção de falas deste primeiro recorte exposto foram analisadas as respostas às perguntas sobre o interesse em viajar após visualizar imagens no Instagram. Como verificado, os respondentes apreendem a rede social como um espaço em que observam imagens que despertam sensações que podem levá-los ao interesse em consumir viagens.

Na categoria 'influência no consumo de viagens', primeira apresentada, encontra-se a resposta direta ao objetivo global do estudo. Para construção desta categoria, foram analisadas as respostas às perguntas sobre o que atrai a atenção nas fotografias de viagens de amigos, o interesse em viajar após visualizar imagens no Instagram e as viagens já realizadas para destinos turísticos conhecidos por meio do Instagram.

Viajar para um lugar não, mas já fiz passeios em viagens que eu não teria visto se não fosse o Instagram (E6).

Sim, agora estou indo para Buenos Aires por conta da influência de uma amiga que postou todos os dias não só fotos, como dicas de onde se hospedar, dicas de passeios e dicas do que fazer. Eu acompanhei todo o passeio (E8).

Eu acho que há vontade de conhecer. Você vê as pessoas num passeio, ou em um restaurante, ou numa festa e aí eu acho que dá vontade, né? (E2).

Eu já fui pro Rio, depois de ver fotos. Acho que incentiva. Ah, quero ir ao Cristo Redentor, quero bater uma foto embaixo do Cristo. Foi ótimo (E2).

Sinto [vontade]. Sinto sim. Tem gente que mora fora que eu sigo que eu acho muito legal e tenho vontade de visitar o local (E5). 
Já viajei para Icaraizinho de Amontada [...] Depois de ter visto as fotos. Me hospedei no mesmo hotel (E5).

O primeiro recorte informa que o respondente não 'viajou' para um local por influência direta do Instagram, mas durante sua viagem ocorreram passeios que só foram possíveis após visualização da rede social. Esta consequência apresenta-se derivada de uma relação de mediação entre o que o usuário observa e que decisões tomar no destino turístico - após a viagem. Na fala de 'E8' é possível observar outra relação de influência, pois se é afirmado que a viagem que irá realizar foi derivada do acompanhamento diário da viagem de uma amiga.

No recorte 'E2' deste trecho, verifica-se a 'vontade' desperta por aquele que visualiza pessoas em festas, passeios ou restaurantes. Este entrevistado também realizou viagens (Rio de Janeiro), por ver fotografias de amigos na rede social. No último trecho, os amigos do usuário que moram fora despertam a vontade de viajar do respondente (E5). Ele também já identificou uma viagem realizada após visualizar imagens no Instagram de amigos e trocar informações com eles.

Estes trechos permitem argumentar em favor de uma influência percebida e que direciona decisões para escolha de destinos turísticos - tal como Buenos Aires e Icaraizinho de Amontada, nos exemplos - e passeios ou serviços turísticos oferecidos no destino - tal como nos demais. Na categoria sobre interação, motivada através de perguntas como 'você costuma comentar ou curtir imagens de viagens no Instagram?', identificam-se os aspectos que despertam a interação e o tipo de interatividade realizada através do aplicativo.

Comento com eles, com os amigos. (troco informações) de preço, de como foi. (E9)

Sim, já comentei, foi o caso dela (amiga que viajou para Buenos Aires) (E8).

Curtir, eu curto qualquer um, mas comentar é mais quando eu tenho interesse, ou num destino, ou num produto. Eu comento normalmente marcando alguém que tenha interesse em comum com aquilo, ou que eu ache que tenha (E6).

Curtir é porque a gente curte mesmo [...] porque eu achei a foto interessante, bonita. Comentar já é com menos frequência, comentar já é mais a foto de conhecidos, pessoas mais próximas (E3).

Através de curtidas e comentários, os entrevistados desenvolvem uma interação através de imagens publicadas, tornando a rede social um instrumento de comunicação pós-massivo através das funcionalidades oferecidas. $\mathrm{O}$ aplicativo, além de constituir um meio de facilitar a interatividade e o relacionamento entre as pessoas, também é utilizado como fonte de informação autêntica, já que os usuários, além de compartilhar seus dados pessoais, dividem suas opiniões sobre diversos assuntos, como a rotina diária, dicas e sugestões (ABBADE et al., 2014).

O Instagram como plataforma de rede social permite aos usuários construir interações, negociar com os pares ao estabelecer um diálogo sobre o conteúdo de uma fotografia. Por meio de uma imagem publicada por um ator no Instagram, opiniões e valores são emitidos, diversos usuários podem se envolver, construindo uma interação mútua, dialógica (FREITAS et al., 2014). Quando questionados sobre utilização de marcação de pessoas, mapas, hashtags, os entrevistados os identificaram dentre as ferramentas utilizadas. 
Marcar os amigos não (tenho o hábito), mas a localização sim. Quando a gente vê, dependendo do usuário, ele tem o cuidado de marcar a localização (E5).

Às vezes eu coloco o local e sempre marco quem tá comigo (E2).

Nesta categoria, os respondentes utilizam a ferramenta de marcação, principalmente de pessoas, para complementar as postagens sobre viagens. Esta é mais uma forma de interação, que agora se realiza através de qualquer ação que simbolize participação, tomada de turno, como curtidas, compartilhamentos, marcação de pessoas e comentários (RECUERO, 2013). Dentre outros fatores que estimulam o consumo de viagens, os respondentes identificaram que as informações contidas nas legendas, o conteúdo e a discrição também são determinantes para a decisão de consumo.

(Um amigo) posta a foto e escreve. É um texto, é bem grande, eu gosto de ler, tem gente que não tem paciência. [...] Ele põe sentimento, coisas cheias de significado, é escritor, é um cara altamente culto (E7).

Inclusive eu achei interessante a forma como ela (amiga) descrevia, que não foi de uma forma exibicionista foi informativa. [...] Quando é exibicionista eu nem olho. Agora quando realmente tem muita informação, aonde foi, quando foi, como foi, sem mostrar a pessoa ali (E8).

Em Buenos Aires postava várias informações do lugar, das atrações Caminito, La Boca, Tango, cemitério (E3).

Nesse recorte, foi verificado que as informações contribuem para despertar o interesse em um destino turístico. O entrevistado 'E7' admira as postagens de viagem de um amigo que explora através de textos, informações e sentimentos nas legendas. O respondente inclusive identificou que gostaria de fazer uma viagem com informações dele. 'Quando a gente casar, ele que vai fazer o nosso roteiro, pra onde a gente for, e ainda mais se for a Europa, porque ele é um cara que sabe muito'.

O último entrevistado, E3, durante a entrevista, lembrou que um seguidor do Instagram, a partir de suas postagens, trocou informações sobre o destino Buenos Aires. Apesar de não ser o foco do estudo, durante a evolução das entrevistas, uma tendência no Instagram de perfis profissionais sobre viagens foi identificada.

O natgeo bota uma foto de umas montanhas lá no Canadá, um rio, meio que na primavera, várias cores... Aquele lugar assim fantasticamente muito bonito então eu fico com vontade na hora de ir pra lá. [...] Por exemplo, o Havaí, num dá vontade de ir não quando tu vê as fotos do Clark Litle? (E1).

Você vê alguma blogueira famosa que vai pra tal canto, vai pra tal restaurante, aí você quer ir também (E2).

Eu até sigo o beautiful places, wonderful places, tem muitas dicas, mas aí são viagens de sonho, né, sonho de consumo, no termo turístico. Perfis de fotografia, de locais específicos. Eu sigo muito um perfil chamado folk magazine, da costa do pacífico dos EUA e Canadá. Muito bonito. Dá vontade de ir (E3).

Eu sigo perfis de viagem, mais de um, se não me engano. Aprendiz de viajante é um que com certeza eu sempre vejo. Normalmente foto de viagem, ou são dele ou são desse pessoal meio mais profissional, tipo blogueira (E6).

Através de perguntas como 'você sente vontade de viajar vendo imagens de viagem de pessoas que você segue no Instagram', a resposta dos entrevistados apontou um achado, uma tendência de seguir perfis profissionais, seja de blogueiros de viagem, como o 'aprendiz de viajante', do E6, seja de perfis especializados em de fotografia, como o Natgeo e Clark Little, apontados por E1. 
Perfis de divulgação de locais exclusivos, como folk magazine, apontado por E3, também estimularam nos entrevistados o desejo de conhecer os locais retratados. Esta tendência dos 'instabloggers' ou 'Instagrammers', geralmente perfis de profissionais do Instagram, no entanto, pode gerar o efeito contrário. Apenas o entrevistado ' $E 6^{\prime}$ afirmou já ter seguido influência de blogueiras para decidir um destino turístico. A falta de identificação com blogueiros e pessoas famosas no Instagram é um fator que, dependendo do usuário, desperta ou não a influência na decisão de uma viagem. Entre os apontamentos destacados, vemos que a realidade econômica de alguns perfis que os respondentes seguem não é semelhante à sua condição. Os entrevistados costumam encontrar nas postagens de amigos mais informações e identificação.

Os famosos vão tipo assim, pra Dubai, Los Angeles, não dá pra mim, ir pra Dubai. (E9)

Os que eu sigo são de um pessoal meio metido a chique, eles não fazem muito turismo nacional (E6).

Quando eu vejo tipo essas blogueiras, eu acho um saco. Eu acho bacana, eu admiro, legal a menina e tal, mas eu acho meio sacal porque é uma realidade que jamais seria a minha, não é o que eu gostaria (E7).

Eu fui almoçar no iate (Recife), que eu nem sabia que tinha, apesar de já ter ido umas dez vezes a Recife. Nunca tinha almoçado lá no iate. Mas a Vic Ceridono (blogueira) botou um vídeo com aquela outra que é pernambucana, (do blog) Garotas Estúpidas. Elas almoçaram no iate, deram dicas, a gente acabou indo lá e realmente era imperdível. Eu tinha visto essa indicação dela (E6).

Já segui dicas de amigos, vendo amigo indo pra algum restaurante, ou vendo amigo em algum lugar ou viagem (E2).

Se inserir no meio também, tem muita gente viajando, você também quer (E4).

Costumo ver fotos de amigos. Não são pessoas aleatórias. São amigos de verdade que eu sigo no Instagram (E5).

Para estes respondentes, a relação de proximidade é mais íntima que apenas social. A influência dos amigos gera mais confiança para o usuário seguir as dicas ou interagir com usuários amigos. "Laços fortes são aqueles que se caracterizam pela intimidade, pela proximidade e pela intencionalidade em criar e manter uma conexão entre duas pessoas. Os laços fracos, por outro lado, caracterizam-se por relações esparsas, que não traduzem proximidade e intimidade." (RECUERO, 2009).

A proximidade dos laços ainda influência a tomada de decisão dos usuários do Instagram, que também deve envolver outros aspectos. Esta aproximação é, inclusive, importante para um aconselhamento posterior à visualização das imagens da viagem. Fora das redes sociais, os amigos costumam trocar informações sobre os destinos turísticos de interesse. Para finalizar, identifica-se que além dos laços de proximidade, outros aspectos pessoais influenciam os entrevistados no consumo de destinos turísticos.

Um amigo meu já veio pedir dicas de Buenos Aires depois que viu minhas fotos de lá (E3).

Eu acompanhei todo o passeio (de uma amiga para Buenos Aires). Foram 15 dias e eu estava decidindo o que fazer, qual o roteiro, achei interessante. [...] daí eu passei uma mensagem pra ela, e ela começou a me passar dicas de agências e de guias locais. Aprofundamos por mensagens (E8).

Não teve um lugar que depois de eu ter visto a foto no Instagram. Mas se eu tivesse tempo e dinheiro, eu teria ido para alguns lugares depois de ter visto as fotos (E9).

O que me influência é tempo, orçamento, uma relação dessas coisas (E6) 
Se o dinheiro permitisse, teria conhecido lugares que vi no Instagram. Também as férias, as companhias, toda uma gama de fatores (E3).

Se eu tivesse tempo e dinheiro, eu teria ido para alguns lugares depois de ter visto as fotos (E1).

Apresenta-se neste recorte, a justificativa dos indivíduos para ainda não terem realizado viagens visualizadas através do Instagram, apesar da intenção. Há determinantes na percepção da influência e na tomada de decisão que ultrapassam os limites da vontade, como motivos financeiros e disponibilidade de tempo e companhia.

\section{CONCLUSÕES}

A pergunta guia desta pesquisa - como as redes sociais virtuais influenciam o consumo de viagens? - tem por resposta nesta seção a percepção de uma influência declarada pelos usuários da rede social Instagram. Além dos aspectos explícitos e expressos pelos respondentes há determinadas características implícitas em meio às suas falas que auxiliam na afirmação desta influência. $O$ resultado da análise dos dados também possibilita a compreensão que esta influição não se dá apenas pela rede social per si e exclusivamente, mas na atividade diária de acompanhar outros usuários (pessoas físicas e organizações) e as imagens que publicam em sua timeline.

A internet modifica o comportamento do consumidor de serviços turísticos e o seu processo decisório à medida que amplia o escopo de opções de escolha e possibilita maior interatividade. Web sites de avaliação de hotéis e restaurantes, como o tripadvisor, ferramentas de pesquisa como o Google streetview, além de web sites de hotéis e empresas de transporte como companhias aéreas facilitaram a pesquisa de destinos dos consumidores, sem a necessidade do intermédio de agências de turismo.

O papel do turista assume novos contornos após o aparecimento do paradigma web 2.0, como um agente orgânico e ativo no processo de formação de imagem, por meio direto e espontâneo através das suas contribuições em sites de redes sociais, tornando-se o tipo mais eficaz de agente de projeção de destino turístico (RAFAEL et al., 2014).

As redes sociais complementam esse processo, uma vez que funcionam como uma vitrine da vida de seus usuários, com o compartilhamento de imagens do cotidiano, incluindo o turismo, como um grande álbum de viagens à disposição de todos os seus amigos. Estes novos hábitos modificaram a maneira como são desejados os destinos turísticos, com maior influência do marketing boca a boca gerado pelas imagens compartilhadas nestas mídias.

Os entrevistados deste estudo, em diversos momentos, demonstram algum tipo de influência do Instagram na escolha de um destino turístico, seja através de interação online com amigos ou um aconselhamento após visualização de imagens. Algumas vezes o usuário nem tem a percepção efetiva desta influência. O fator imagem, sozinho, é importante para conquistar os usuários, mas as informações complementares através de legendas e textos bem construídos aumentam as chances de atrair a atenção do internauta do Instagram. 
A interpretação do conteúdo mostrou que a direção de perfis profissionais, principalmente os dedicados à postagem de fotografias e viagens, despertam forte interesse na divulgação de potenciais destinos turísticos. A intangibilidade do destino turístico beneficia-se com esta exposição visual via redes sociais, tornando-o uma imagem tangível e permitindo uma experiência virtual através do Instagram. A formação e a percepção da imagem de um destino turístico através desta rede social aproximam os indivíduos de seus pares, exibindo viagens e experiências de amigos e semelhantes.

\section{REFERÊNCIAS}

ABBADE, E. B.; DELLA FLORA, A.; NORO, G. B.. A influência interpessoal em redes sociais virtuais e as decisões de consumo. Revista de Administração da UFSM, v.7, n.2, 2014.

ATKINSON, R.; FLINT, J.. Accessing hidden and hard-to-reach populations: snowball research strategies. Social research update, v.33, n.1, p.1-4, 2001.

BARDIN, L.. Análise de conteúdo. São Paulo: Edições 70, 2011.

BAUDRILLARD, J.. Power Inferno. Porto Alegre: Sulina, 2007.

BAUER, M. W.; AARTS, B.. A construção do corpus: um princípio para a coleta de dados qualitativos. In: BAUER, M. W.; GASKELL, G.. Pesquisa qualitativa com texto, imagem e som: um manual prático. 10 ed. Petrópolis: Vozes, 2012.

BAUMAN, Z.. Vida para Consumo: a transformação das pessoas em mercadoria. Rio de Janeiro: Zahar, 2008.

COLLIS, J.; HUSSEY, R.. Pesquisa em administração: um guia prático para alunos de graduação e pós-graduação. Porto Alegre: Bookman, 2005.

DARIES-RAMON, N.; CRISTÓBAL-FRANSI, E.; MARTÍNFUENTES, E.; MARINÉ-ROIG, E.. Desarrollo de las TIC en el turismo de nieve: Análisis de la presencia en línea de las estaciones de esquí de España y Andorra. Documents d'Anàlisi Geogràfica, v.63, n.2, p.399-426, 2017.

DENZIN, N. K.; LINCOLN, Y. S.. O planejamento da pesquisa qualitativa: teorias e abordagens. 2 ed. Porto Alegre: Artmed, 2006.

DUARTE, J.. Tecnologia potencializa comunicação no serviço público. Revista Tema: A Revista do Serpro, v.37, n.213, 2012.

FONTCUBERTA, J.. A câmera de Pandora: a fotografi@ depois da fotografia. São Paulo: GGilli, 2012.

FREITAS, A. F.; BENINI, L. F. P.. Interatividade em redes móveis: um estudo sobre as missões no Instagram. Brasília: UnB, 2014.
GASKELL, G.. Entrevistas individuais e grupais. In: BAUER, M. W.; GASKELL, G.. Pesquisa qualitativa com texto, imagem e som: um manual prático. 10 ed. Petrópolis: Vozes, 2012.

MESQUITA, R. F.; MATOS, F. R. N.. Pesquisa qualitativa e estudos organizacionais: história, abordagens e perspectivas futuras. In: COLÓQUIO INTERNACIONAL DE EPISTEMOLOGIA E SOCIOLOGIA DA CIÊNCIA DA ADMINISTRAÇÃO, 4. Anais. Florianópolis, 2014.

MKONO, M.; TRIBE, J.. Beyond reviewing: Uncovering the multiple roles of tourism social media users. Journal of Travel Research, v.56, n.3, p.287-298, 2017.

MOURA, P. N.. O Marketing de Mídias Sociais e a Influência no Comportamento do Consumidor. Monografia (PósGraduação em Mídias Digitais) - Universidade Estácio de Sá, Rio de Janeiro, 2009.

PATTON, M. Q. Qualitative research and evaluation methods. London: Sage Publications, 2002.

RAFAEL, C.; ALMEIDA, A.. Impacto da informação online na formação da imagem de destino virtual. Dos Algarves: A Multidisciplinary e-journal, n.23, 2014.

RECUERO, R.. Atos de ameaça à face e à conversação em redes sociais na internet. Interações em rede, p. 51-69, 2013.

RECUERO, R.. Redes Sociais na Internet. Sulina: 2009.

SALAZAR, M. M.. Consumir, registrar, compartilhar: a hashtag \#lookdodia na sociedade de consumo. In: SIMPÓSIO NACIONAL DA ABCIBER, 8. Anais. São Paulo: ABCiber, 2014. SCHIFFMAN, L.; KANUK, L.. Comportamento do consumidor. 6 ed. Rio de Janeiro: LTC, 2009.

WOLTON, D.. Internet, e depois?: uma teoria crítica das novas mídias. Sulina: 2003.

XIAO, H. L.; LI, W. F.; CAO, X. B.; TANG, Z. M.. The Online Social Networks on Knowledge Exchange: Online Social Identity, Social Tie and Culture Orientation. Journal of Global Information Technology Management, v.15, n.2, p.424,2012

A CBPC - Companhia Brasileira de Produção Científica (CNPJ: 11.221.422/0001-03) detém os direitos materiais desta publicação. Os direitos referem-se à publicação do trabalho em qualquer parte do mundo, incluindo os direitos às renovações, expansões e disseminações da contribuição, bem como outros direitos subsidiários. Todos os trabalhos publicados eletronicamente poderão posteriormente ser publicados em coletâneas impressas sob coordenação da Sustenere Publishing, da Companhia Brasileira de Produção Científica e seus parceiros autorizados. Os (as) autores (as) preservam os direitos autorais, mas não têm permissão para a publicação da contribuição em outro meio, impresso ou digital, em português ou em tradução. 